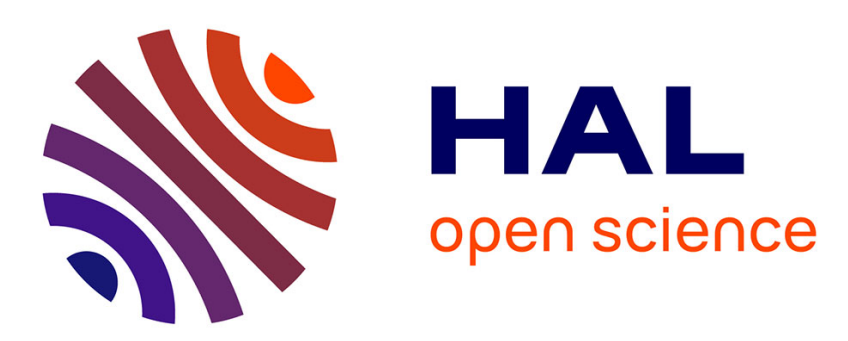

\title{
New approach for kinetic parameters determination for hydrothermal oxidation reaction
}

David Mateos, Juan R. Portela, Jacques Mercadier, Frederic Marias, Christine Marraud, François Cansell

\section{- To cite this version:}

David Mateos, Juan R. Portela, Jacques Mercadier, Frederic Marias, Christine Marraud, et al.. New approach for kinetic parameters determination for hydrothermal oxidation reaction. Journal of Supercritical Fluids, 2005, 34 (1), pp.63-70. 10.1016/j.supflu.2004.10.013 . hal-00004802

\section{HAL Id: hal-00004802 https://hal.science/hal-00004802}

Submitted on 15 Jun 2005

HAL is a multi-disciplinary open access archive for the deposit and dissemination of scientific research documents, whether they are published or not. The documents may come from teaching and research institutions in France or abroad, or from public or private research centers.
L'archive ouverte pluridisciplinaire HAL, est destinée au dépôt et à la diffusion de documents scientifiques de niveau recherche, publiés ou non, émanant des établissements d'enseignement et de recherche français ou étrangers, des laboratoires publics ou privés. 


\section{New approach for kinetic parameters determination for hydrothermal oxidation reaction}

David Mateos $^{\mathrm{a}}$, Juan R. Portela ${ }^{\mathrm{b}}$, Jacques Mercadier ${ }^{\mathrm{c}}$, Frédéric Marias ${ }^{\mathrm{c}}$, Christine Marraud $^{\mathrm{d}}$, François Cansell ${ }^{\mathrm{a} *}$,.

${ }^{a}$ Institut de Chimie et de la Matière Condensée de Bordeaux, 87 avenue du Docteur Albert Schweitzer, 33608 Pessac Cedex, France.

${ }^{b}$ Department of Chemical Engineering, Food Technology and Environmental Technologies. Faculty of Sciences. University of Cádiz, 11510 Puerto Real (Cádiz), Spain.

'Laboratoire de Thermique, Energétique et Procédé, ENSGTI, Rue Jules Ferry, BP 7511, 64075 Pau, France.

${ }^{\text {d} S N P E ~ M a t e ́ r i a u x ~ E n e r g e ́ t i q u e s, ~ a v e n u e ~ G a y ~ L u s s a c, ~} 33166$ Saint Médard en Jalles, France.

* Corresponding Author

e-mail: cansell@icmcb-bordeaux.cnrs.fr

Phone: (+33)0540002673; Fax: (+33)0540002671 


\begin{abstract}
The purpose of this study is to test Runge-Kutta algorithm to obtain reliable kinetic parameters for the hydrothermal oxidation of organic compounds. A tubular reactor system was used to carry out the oxidation of several model compounds: acetic acid, methanol and phenol. All experiments were performed in isothermal conditions in a temperature range varying from $250^{\circ} \mathrm{C}$ to $500^{\circ} \mathrm{C}$ and at a constant pressure of $25 \mathrm{Mpa}$. Three different methods, namely pseudo first order kinetics, multiple linear regression and Runge-Kutta algorithm, were used to determine the kinetic parameters. Results obtained by these different methods were similar, so that Runge-Kutta algorithm was validate for the determination of kinetic parameters. In contrast with the pseudo first order kinetics and the multi linear regression, Runge-Kutta algorithm was more convenient for the kinetic parameter determination starting from experiments performed at the laboratory scale or in industrial scale pilot plant facilities.
\end{abstract}

Keywords: Hydrothermal oxidation, phenol, acetic acid, methanol, kinetic parameters 


\section{Introduction}

Oxidation of wastewaters at high pressure and temperature, so-called hydrothermal oxidation treatment (HOT), is an efficient alternative to conventional methods such as biological treatments or common chemical processes in the treatment of highly contaminated wastewaters with an organic concentration between 10 to 70 g/l [1,2,3]. HOT can operate in conditions below or above the critical point of water $\left(374.2^{\circ} \mathrm{C}\right.$ and 22.1 $\mathrm{MPa}$ ). Below the critical point of water, the process is called wet air oxidation (WAO) and it typically operates at temperatures and pressures ranging from 200 to $330^{\circ} \mathrm{C}$ and from 2 to $20 \mathrm{MPa}$, respectively [4]. Above the critical point of water, the process is called supercritical water oxidation (SCWO) and it typically implies pressures and temperatures varying between 400 and $650^{\circ} \mathrm{C}$ and between 25 and $35 \mathrm{MPa}$, respectively [5]. In these last conditions, the treatment of organic compounds that contain carbon, hydrogen, nitrogen and oxygen leads to the output liquid effluent and gas effluent that can be released in natural media without post-treatment [6]. Moreover, the liquid output can be used for industrial or agricultural applications.

In order to scale up reactors for HOT of industrial wastewaters, kinetic parameters of hydrothermal oxidation reaction and heat transfer are required [7]. In the last two decades, many authors have studied kinetic parameters of hydrothermal oxidation reaction of several model compounds, like acetic acid, methanol and phenol. Portela et al. [8] have demonstrated, for kinetic studies on phenol, that the parameters obtained in WAO and SCWO could not be used in operating conditions different from those in which they were obtained. More generally, the kinetic parameters were relative to the reactor system in which the experimental data were obtained and were only applicable for the scale-up of a similar reactor concept. In this way, in order to predict or simulate the behaviour of industrial pilot plant facilities, extensive experimental works are needed, 
especially the effects of main process parameters such as temperature, and both organic and oxygen concentrations. Concerning heat transfer, this parameter was already well investigated and simulation tools are available $[9,10]$. The purpose of this study was to test Runge Kutta algorithm in order to obtain reliable kinetic information for hydrothermal oxidation of organic compounds. Thus, three different approaches were tested and compared to determine the kinetic parameters for HOT of 3 model compounds, i.e., acetic acid, methanol and phenol.

\section{Experimental}

Fig. 1 shows a schematic diagram of the pilot plant facility developed in our laboratory [11]. This pilot plant facility was able to treat up to $2.8 \mathrm{~kg} \cdot \mathrm{h}^{-1}$ aqueous wastes in a temperature range of 200 to $600^{\circ} \mathrm{C}$, at pressures up to $30 \mathrm{MPa}$. Main units of this equipment were connected to a data acquisition and control unit controlled by Labview software (National Instrumentation). This system permited to select, control and save main parameters as organic feed and oxygen flow rates, temperature of pre-heater and reactor and system pressure.High-pressure pump LEWA pressurized the aqueous feed solution, typically at a flow rate of $1 \mathrm{~kg} \cdot \mathrm{h}^{-1}$. Before entering the reactor, this feed was preheated at the desired reaction temperature by an electric heater $(1.5 \mathrm{~kW})$ along $9 \mathrm{~m}$ of 316 SS tubing with an internal diameter of $1.6 \mathrm{~mm}$. The oxidant feed was pure oxygen pressurized by a Haskel compressor that injected the oxygen at $25 \mathrm{MPa}$, without preheating, at the input of the reactor. A mass flow meter (Brooks 5850S) allowed the selection and control of the desired flow rate in the range of 0 to $100 \mathrm{~g} \cdot \mathrm{h}^{-1}$.The reactor was made of Inconel 625 (36 m length and $1.6 \mathrm{~mm}$ internal diameter). Twenty eight thermocouples were attached to the external surface. The working reaction temperature was controlled by three external electrical heaters (1.5 $\mathrm{kW}$ each one) connected to a PID 
controller. The reactor was isolated by a calcite jacket.At the output of the reactor, the effluent was cooled by a counter current heat exchanger and afterwards, the system pressure was reduced by using a backpressure regulator. The product stream was then separated into liquid and vapor phases. For liquid samples, Chemical Oxygen Demand (COD) was performed according to the French normalized method for water and wastewater analysis [12]. The accuracy of the COD measurements was $\pm 5 \%$ since the organic matter studied was water soluble. The initial concentration of organic compounds was 10 g. l $^{-1}$ in terms of COD. All experiments were performed in duplicate. The experiments were carried out in isothermal conditions with temperatures ranging from 250 to $500^{\circ} \mathrm{C}$ and at a constant pressure of $25 \mathrm{MPa}$. In the case of phenol, since it was easily oxidized, temperature and residence time ranges of 250 to $350^{\circ} \mathrm{C}$ and 50 to $250 \mathrm{~s}$, respectively, were selected. For methanol and acetic acid, since they were more persistent compounds, temperature and residence time ranged from 400 to $500^{\circ} \mathrm{C}$ and 10 to $60 \mathrm{~s}$, respectively. The choice of these temperature and pressure domains allowed the transformation of $10 \%$ to $90 \%$ of the organic matter that was required for kinetic studies.

\section{Results}

\section{1. Pseudo first order kinetics}

Experiments were carried out assuming a zero order for oxygen concentration since oxygen excess was of one order of magnitude regarding stoichiometry of the oxidation reaction. The continuous flow reactor was in steady state. Thus, the global kinetic equation could be expressed as follows:

$$
-\frac{d[C O D]}{d \tau}=k[C O D]
$$


where [COD] was the chemical oxygen demand $\left(\mathrm{mol}^{-1} \mathrm{l}^{-1}\right), \tau$ the residence time in $\mathrm{s}$, and $\mathrm{k}$ the reaction rate coefficient $\left(\mathrm{s}^{-1}\right)$ assuming an Arrhenius law:

$$
k=A \exp \left(-\frac{E_{a}}{R T}\right)
$$

where A was the pre-exponential factor $\left(\mathrm{s}^{-1}\right), \mathrm{E}_{\mathrm{a}}$ the activation energy $\left(\mathrm{J}_{\mathrm{mol}}{ }^{-1}\right), \mathrm{R}$ the universal gas constant (8.314 J.mol ${ }^{-1} \mathrm{~K}^{-1}$ ) and T the temperature (K).

In expression (1), COD concentration was used instead of the organic molecule concentration. Indeed, COD concentration was chosen as a parameter to describe the global kinetics of the organic compound transformation into $\mathrm{CO}_{2}$ and $\mathrm{H}_{2} \mathrm{O}$. Moreover, this approach avoided taking into account the formation of intermediate organic compounds. Integration of equation (1) on the residence times of the organic compounds in the reactor led to the following equation:

$$
-\ln \frac{[C O D]}{[C O D]_{0}}=k \tau
$$

where $[\mathrm{COD}]_{0}$ was the initial chemical oxygen demand (mol. ${ }^{-1}$ ), [COD] the chemical oxygen demand (mol. $\left.{ }^{-1}\right)$ at $\tau$, and $\mathrm{k}$ the reaction rate coefficient $\left(\mathrm{s}^{-1}\right)$.

The residence time was calculated by addition of the mass flow rates of oxygen and liquid on the basis of the thermodynamic data of oxygen [13] and pure water [14]. The concentration of organic compounds lower than 5 g.l $\mathrm{l}^{-1}$ justified this last assumption. For each temperature, $\mathrm{k}$ was obtained by a linear regression on experimental [COD] values and residence times, according to equation (2). For these experiments, the ratio $[\mathrm{COD}] /[\mathrm{COD}]_{0}$ varied from 11 to $88 \%$. Fig. 2 shows the Arrhenius plot for the different $\mathrm{k}$ values obtained at the different temperatures for the hydrothermal oxidation experiments on acetic acid, phenol and methanol. Arrhenius parameters (pre- 
exponential factor and activation energy) were calculated using a linear regression. Results are reported in Table 1.

\section{2. Multiple linear regressions}

A set of experiments was performed in order to calculate the oxygen order in the hydrothermal oxidation reaction. The experimental data were analyzed using a multi linear regression method. The continuous flow reactor was in steady state, so that the global rate of transformation of organic compounds in $\mathrm{CO}_{2}$ by hydrothermal oxidation could be expressed as follows:

$$
\text { rate }=-\frac{d[C O D]}{d \tau}=A \cdot \exp \left(-\frac{E_{a}}{R T}\right)[C O D]^{a}\left[\mathrm{O}_{2}\right]^{b}\left[\mathrm{H}_{2} \mathrm{O}\right]^{c}
$$

where a, b, and c were the reaction orders of organic matter, oxygen, and water, respectively. The reaction rate coefficient was expressed in the Arrhenius form, where A was the pre-exponential factor $\left(\left(\mathrm{mol}_{\mathrm{l}} \mathrm{l}^{-1}\right)^{1-\mathrm{a}-\mathrm{b}-\mathrm{c}} \cdot \mathrm{s}^{-1}\right)$ and $\mathrm{E}_{\mathrm{a}}$ the activation energy $\left(\mathrm{J} \cdot \mathrm{mol}^{-1}\right)$. For similar reasons as previously mentioned, COD concentration was preferred to organic molecule concentration. As already published, the reaction order of organic compounds in HOT could be assumed equal to unity [9]. Besides, in a reaction medium containing more than $90 \%$ of water, the reaction order of water could be considered equal to zero. On these bases, equation (4) was simplified to the following one:

$$
\text { rate }=-\frac{d[C O D]}{d \tau}=A \cdot \exp \left(-\frac{E_{a}}{R T}\right)[C O D]\left[O_{2}\right]^{b}
$$

In order to treat equation (5) with the multiple linear regression analysis, the following steps were applied: 
1) Experiments were performed in order to get data characterized by the same oxygen stoichiometry (Fig.3-5);

2) For each group and at each temperature, the evolution of COD concentration had to be plotted versus residence time. In all cases, accurate results were obtained using an exponential regression as follows:

$$
[C O D]=[C O D] \cdot e^{(-m \tau)}
$$

where $\mathrm{m}$ was the fitting parameter and $\tau$ the residence time (s). Figs 3, 4 and 5 show the results obtained for the 3 model compounds studied.

3) The derivation of equation (6) allowed to calculate the global reaction rate for the same residence time, for each compound:

$$
-\frac{d[C O D]}{d \tau}=[C O D]_{0} \cdot m \cdot e^{(-m \tau)}
$$

Since all experiments were carried out at a constant $[\mathrm{COD}]_{0}$ and since $[\mathrm{COD}]$ was calculated for the same $\tau$, it was possible to express the reaction rate as:

$$
\text { rate }=-\frac{d[C O D]}{d \tau}=A^{*} \cdot \exp \left(-\frac{E_{a}}{R T}\right)\left[O_{2}\right]^{b}
$$

where $A^{*}=A[C O D]=\mathrm{A}[C O D]_{0} \cdot e(-m \tau)$ was a constant value.

Finally, equation (8) could be expressed as a linear equation. Starting from the [COD] decreasing rate and the oxygen concentration, the characteristic parameters $E_{a}, A$ and $b$ were determined by the multiple linear regression of equation (9). Results obtained for the 3 model compounds are reported in Table 1.

$$
\ln \left(-\frac{d[C O D]}{d \tau}\right)=\log A^{*}-\frac{E_{a}}{R} \frac{1}{T}+b \cdot \log \left[O_{2}\right]
$$

\section{3. Runge Kutta algorithm}


When analyzing the experimental data using the Runge Kutta algorithm, the oxygen concentration at any time was expressed as a function of the initial oxygen concentration and the final COD concentration. The oxygen in the reaction medium could be expressed as follows:

$$
\left[\mathrm{O}_{2}\right]=\left(\left[\mathrm{O}_{2}\right]_{0}-\left([\mathrm{COD}]_{0}-[\mathrm{COD}]\right)\right)
$$

According to equation (5), the global reaction rate was deduced:

$$
\text { rate }=-\frac{d[C O D]}{d \tau}=k[C O D]^{1}\left(\left[O_{2}\right]_{0}-\left([C O D]_{0}-[C O D]\right)\right)^{b}
$$

where $[\mathrm{COD}]_{0}$ and $\left[\mathrm{O}_{2}\right]_{0}$ corresponded to $\tau=0$; $\mathrm{k}$ was the global kinetic constant regarding COD disappearance.

This differential equation was solved numerically by a method using the Runge-Kutta algorithm managed by a Fortran program. In this algorithm, the integration interval from 0 to the global residence time $\left(\tau_{N}\right)$ was divided into $N$ sub-intervals with $h=\tau_{n} / N$. The set of equations used in this method was reported hereafter:

$$
\left\{\begin{array}{l}
k_{1}=f\left(\tau_{n}, C O D_{n}\right) \\
k_{2}=f\left(\tau_{n}+\frac{h}{2}, C O D_{n}+h \frac{k_{1}}{2}\right) \\
k_{3}=f\left(\tau_{n}+\frac{h}{2}, C O D_{n}+h \frac{k_{2}}{2}\right) \\
k_{4}=f\left(\tau_{n}+h, C O D_{n}+h k_{3}\right) \\
\operatorname{COD}_{n+1}=C O D_{n}+\frac{h}{6}\left(k_{1}+2 k_{2}+2 k_{3}+k_{4}\right)
\end{array}\right\} n=0, \ldots . N-1
$$

where: $\tau_{\mathrm{n}}=\mathrm{n} \mathrm{h} ; \mathrm{k}_{1}, \mathrm{k}_{2}, \mathrm{k}_{3}$, $\mathrm{k}_{4}$ were the internal parameters defined in the Runge Kutta algorithm; $[\mathrm{COD}]_{\mathrm{n}}$ and $[\mathrm{COD}]_{\mathrm{n}+1}$ were the calculated COD concentrations at $\tau_{\mathrm{n}}$ and $\tau_{\mathrm{n}+1}$, respectively. $\mathrm{k}$ and $\mathrm{b}$ values were fixed starting values from literature for the first run of algorithm. $[\mathrm{COD}]_{\mathrm{N}}$, that corresponded to the COD concentration calculated for global 
residence time, was obtained for all experiments performed on the model molecules at one temperature. At least 13 experiments were carried out on each model molecule, for each temperature. These $[\mathrm{COD}]_{\mathrm{N}}$ were compared to the final experimental COD concentrations ([COD $]_{\exp }$ ) and an adjustment of both $\mathrm{k}$ and $\mathrm{b}$ values were performed in order to get the best fitting between the calculated $[\mathrm{COD}]_{\mathrm{N}}$ and experimental ones. Starting from the calculated values of $\mathrm{k}$ at different temperatures, activation energy of the 3 chemical reactions were determined by linear regression in an Arrhenius plot. Figure 6 and Table 1 present the results obtained.

\section{Discussion}

First, it was worth noting that the power-law rate expressions were equations that only reflected the general trend of the experimental data. They did not describe in detail the complex oxidation reaction. The way to better understand and control the oxidation reaction goes through the knowledge of the kinetic model, consisting of elementary reaction steps. This was not the main goal of this work that focused on the validation of simple methods for experimental data analysis in order to get real waste kinetic parameters for the scale-up of hydrothermal oxidation units. As already mentionned, the global reaction orders published in the literature were only relevant of the reaction conditions used in the kinetic study. Experimental factors such as the geometry of the injection port that allows the mixing of the organic matter and the oxygen, affected the global kinetic parameters obtained [15]. Indeed, one of the assumptions of power-law rate expressions was an instantaneous mixing of wastewaters with oxygen. Some simulations have clearly shown that this was not the case [16]. Although the activation energy was not an intrinsic parameter, it could be considered as a parameter that predicts the temperature dependence upon the COD disappearance rate in the operating 
conditions of the study. Thus, this kinetic parameter can be used for the scale-up of industrial units which are developed with the same concept and flowsheet as the pilot plant facility.

Data obtained with experimental conditions similar to those used in this work could be accurately compared. Thus, only studies using the following characteristics were considered: i) non catalytic hydrothermal oxidation; ii) plug flow reactor (without packed bed); iii) pressure close to $25 \mathrm{MPa}$; iv) temperature ranges between 250 and $350^{\circ} \mathrm{C}$ for phenol and 400 and $500^{\circ} \mathrm{C}$ for acetic acid and methanol; v) pure oxygen as oxidant. Moreover, besides the simple comparison of the Arrhenius parameters (A and $E_{a}$ ) reported in Table 1 , for acetic acid [17,18,19], methanol [20] and phenol $[18,8]$, the reaction orders of organic, oxygen and water were also reported in Table 1 . This implied the choice of a same fixed set of operating conditions that were defined hereafter:

- $\quad[\mathrm{COD}]_{0}=0.3125 \mathrm{mol.}^{-1}$ or $\left[\mathrm{CH}_{3} \mathrm{COOH}\right]=0.156 \mathrm{~mol}^{.-1} ;\left[\mathrm{CH}_{3} \mathrm{OH}\right]=0.208 \mathrm{mol.}^{-1}$; $\left[\mathrm{C}_{6} \mathrm{H}_{5} \mathrm{OH}\right]=0.045$ mol. $\mathrm{l}^{-1}$

- $\quad 20 \%$ oxygen excess from stoichiometry, so $\left[\mathrm{O}_{2}\right]_{0}=0.375$ mol. $\mathrm{l}^{-1}$

- Temperature of $450^{\circ} \mathrm{C}$ for acetic acid and methanol, and $300^{\circ} \mathrm{C}$ for phenol

Kinetic parameters for pseudo-first order kinetics, obtained with an oxygen excess of one order of magnitude regarding stoichiometry of the oxidation reaction, were in good agreement with those previously published in the literature taking into account the accuracy of our results. It is important to point out that the assumption of hydrothermal oxidation reaction assuming a zero order for oxygen concentration limited drastically the application of the kinetic equation in the simulation of industrial HOT process. The pseudofirst order kinetics did not consider a decrease in the kinetic reaction rate when the oxygen 
concentration decreased significantly in the reactor. It is obvious that an industrial HOT process cannot operate with great oxygen excess, so a kinetic equation that takes into account the effect of oxygen concentration is needed. In this way, experiments were performed in order to calculate the oxygen order in the hydrothermal oxidation reaction. At first, the experimental data were treated by multiple linear regressions as classically used. The kinetic results obtained (Table 1) for acetic acid were close to those previously published. Same agreement was obtained for the kinetic results for phenol (Table 1) and literature data in the same temperature range. In contrast, when the temperature range between 300 and $500^{\circ} \mathrm{C}$ was considered, the kinetic results were different of one order of magnitude. This result remained unexplained.

The kinetic results obtained by linear regression, when the oxygen content was lower and higher than the stoichiometry, were in good agreement with those obtained by pseudo-first order kinetics, with an oxygen excess of one order of magnitude regarding stoichiometry of the oxidation reaction. This validated that the rates determining steps of oxidation reaction were similar when the oxygen content varied from 0.4 to 1.4, regarding the stoichiometry.

The use of multiple linear regressions implied to carry out a set of experiments with the same amount of oxygen at any residence time. This implied to collect numerous experimental data that might be difficult to obtain. Generally, 3 or 4 experimental data were used for the kinetic parameter determination. In this way, Runge Kutta algorithm was used for fitting together all experimental data. The kinetic results obtained (Table 1) for acetic acid, methanol and phenol were close to those obtained in this study with the two other kinetic parameter determination method. We can consider that Runge Kutta algorithm was validated for experimental data treatment in order to get global kinetic 
parameters. This algorithm was a more efficient calculation method for this kind of analysis, because the use of this method allowed simplifying the set-up of experiments by suppression of experiments with the same amount of oxygen at any residence time.

\section{Conclusion}

The main goal of this work was to validate Runge-Kutta algorithm for experimental data analysis in order to get, in a simplest way, the real waste kinetic parameters for the scale up of hydrothermal oxydation units. At first, global kinetic parameter was determined with pseudo-first order kinetics assuming a zero order for oxygen concentration. At second, oxygen order for oxygen concentration on the rate of organic compound oxidation was determined by multiple linear regressions. Based on these two methods of experimental data analysis, Runge-Kutta algorithm was validated for the determination of kinetic parameters starting from experimental data. The main advantages of Runge-Kutta algorithm for experimental data treatments, regarding multi-linear regression method, were: i) the possibility of fitting together all experimental data obtained at the same temperature; ii) the suppression of experiments with the same amount of oxygen at any residence time. Runge-Kutta algorithm could be used for the determination of kinetic parameters of real wastewaters starting from experimental data obtained by the ICMCB pilot scale laboratory and on the two industrial pilot plant facilities developed by HOO company [21]. These pilots were based on a new concept of HOT reactor [22] and a capacity of $100 \mathrm{~kg} / \mathrm{h}$ of waste treatment capacity.

\section{Acknowledgements}


We wish to thank the French "Délégation Générale de l’Armement” for its financial support to this work. 


\section{Figure captions}

Fig. 1. Schematic diagram of the continuous flow reactor system.

Fig. 2. Arrhenius plot for the $\mathrm{k}$ values calculated by pseudo first order kinetics from experimental data obtained at different temperatures for the oxidation of acetic acid, phenol and methanol under oxygen excess. $\mathrm{k}$ values are means $\pm 10 \%$ and resulted of 4 different resident times determined at a constant temperature.

Fig. 3. Evolution of COD versus residence time at different temperatures for experiments of acetic acid oxidation with different amounts of oxygen. COD values are means $\pm 10 \%$ of two independent experiments.

Fig. 4. Evolution of COD versus residence time at different temperatures for experiments of methanol oxidation with different amounts of oxygen. COD values are means $\pm 10 \%$ of two independent experiments.

Fig. 5. Evolution of COD versus residence time at different temperatures for experiments of phenol oxidation with different amounts of oxygen. COD values are means $\pm 10 \%$ of two independent experiments.

Fig. 6. Arrhenius plot for the $\mathrm{k}$ values calculated by Runge Kutta algorithm from experimental data obtained at different temperatures for the oxidation of acetic acid, phenol and methanol. For each organic compound, $k$ values are means of the experimental data reported in Figs 3-5, at a constant temperature. 


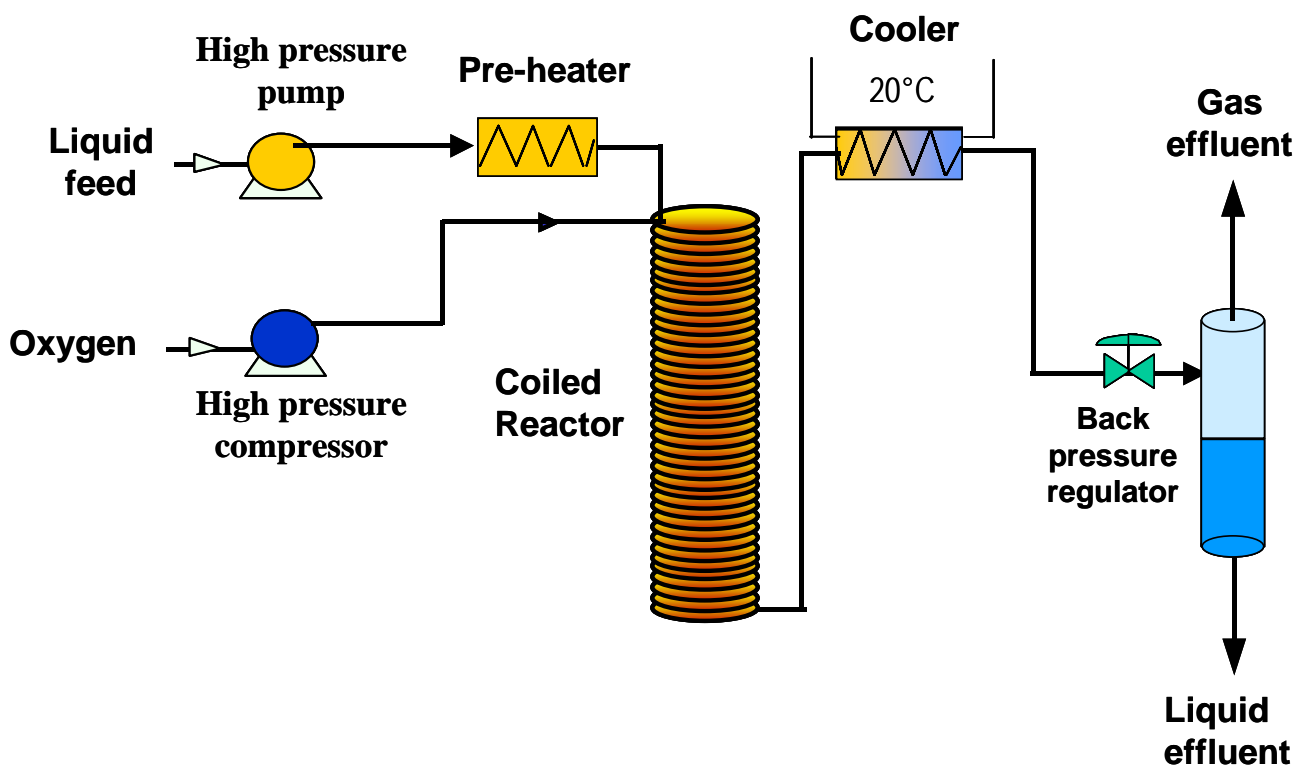

Figure 1 


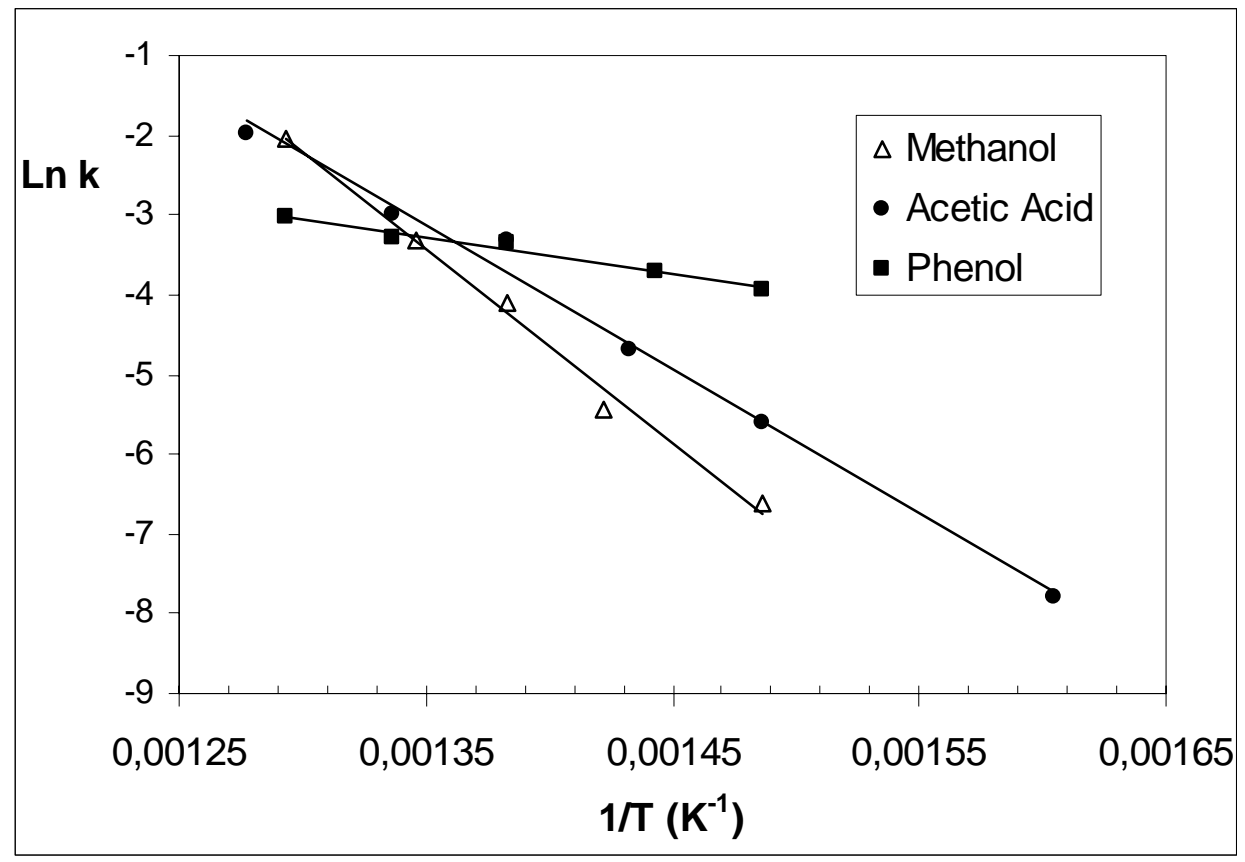

Figure 2 

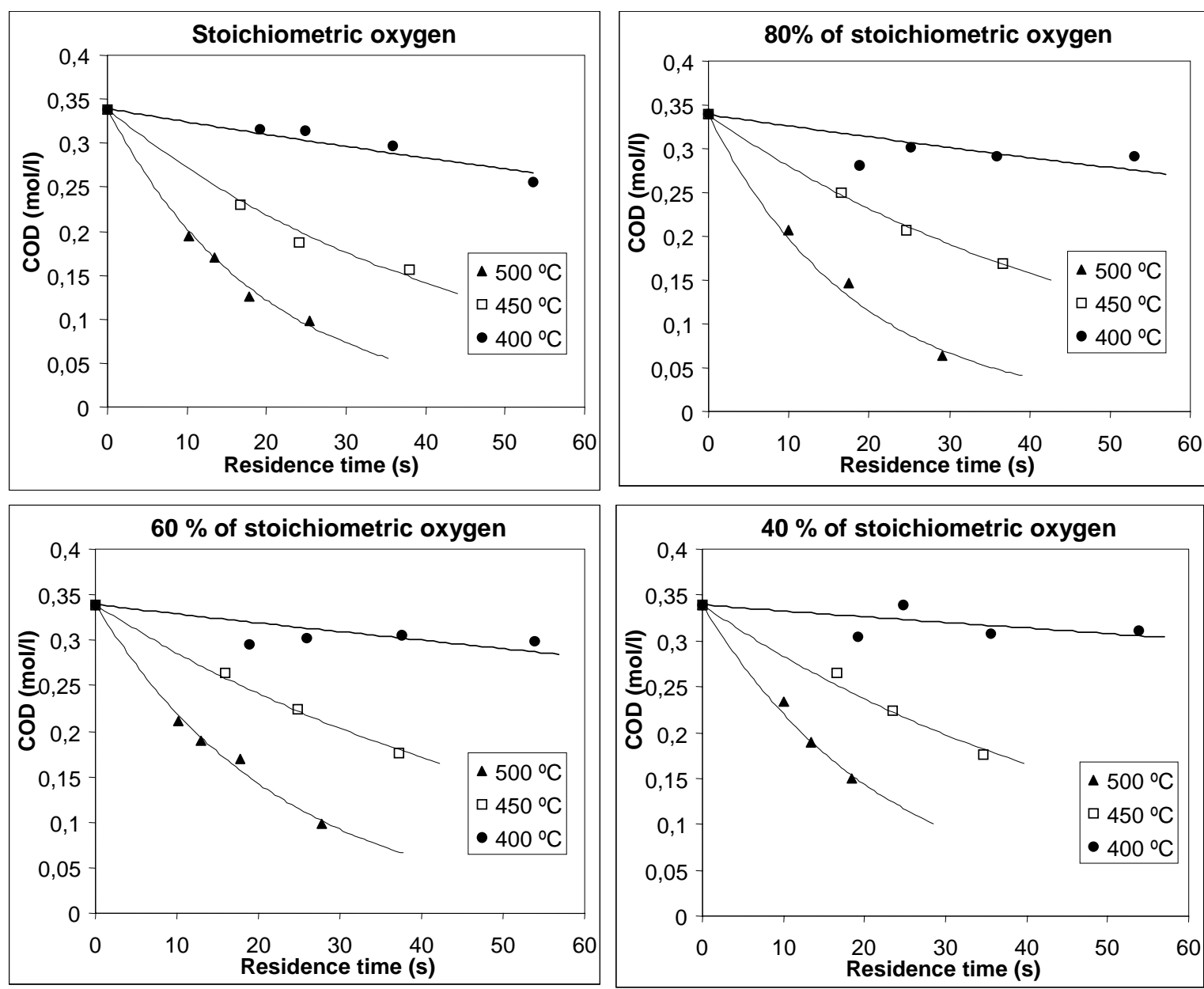

Figure 3 

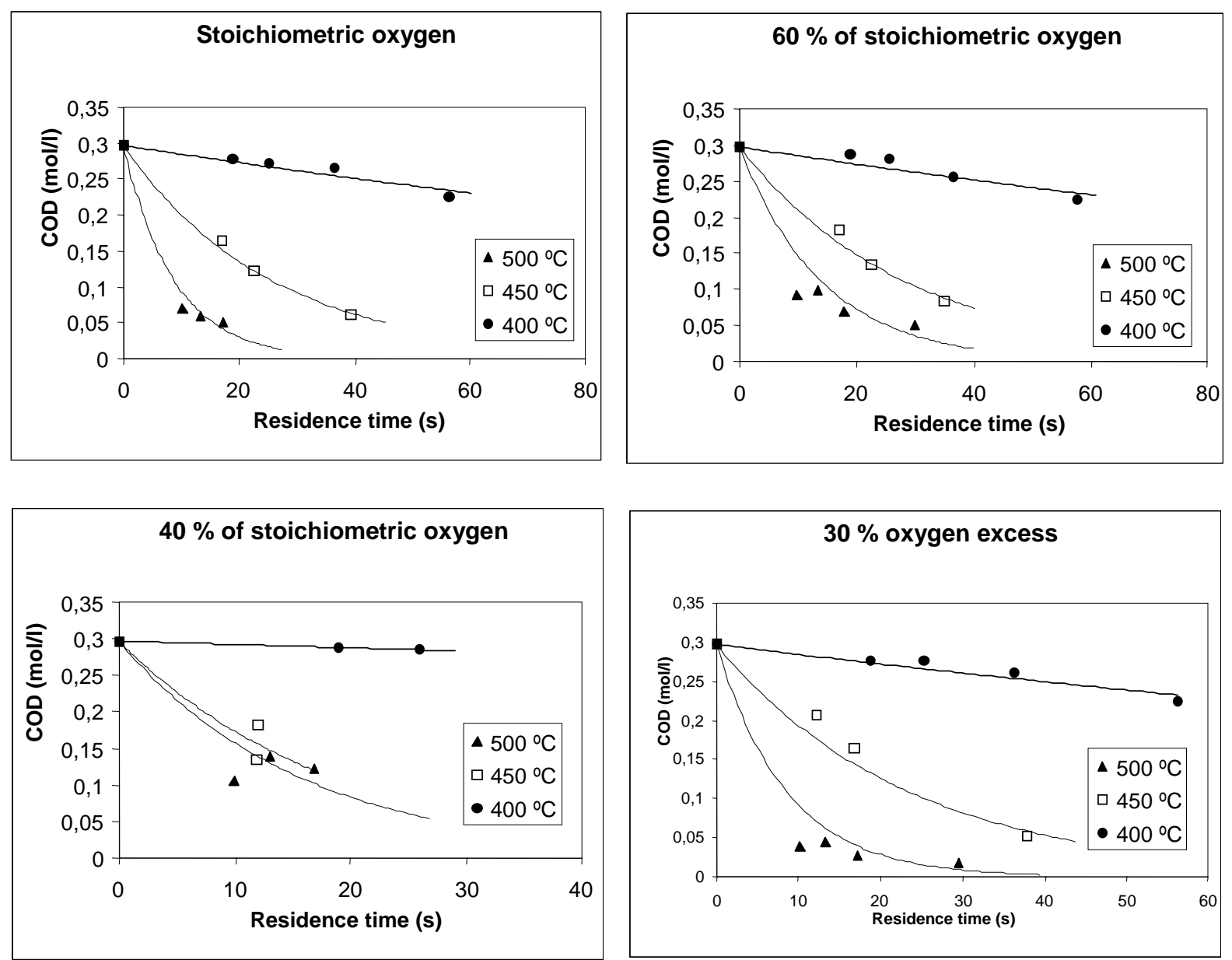

Figure 4 

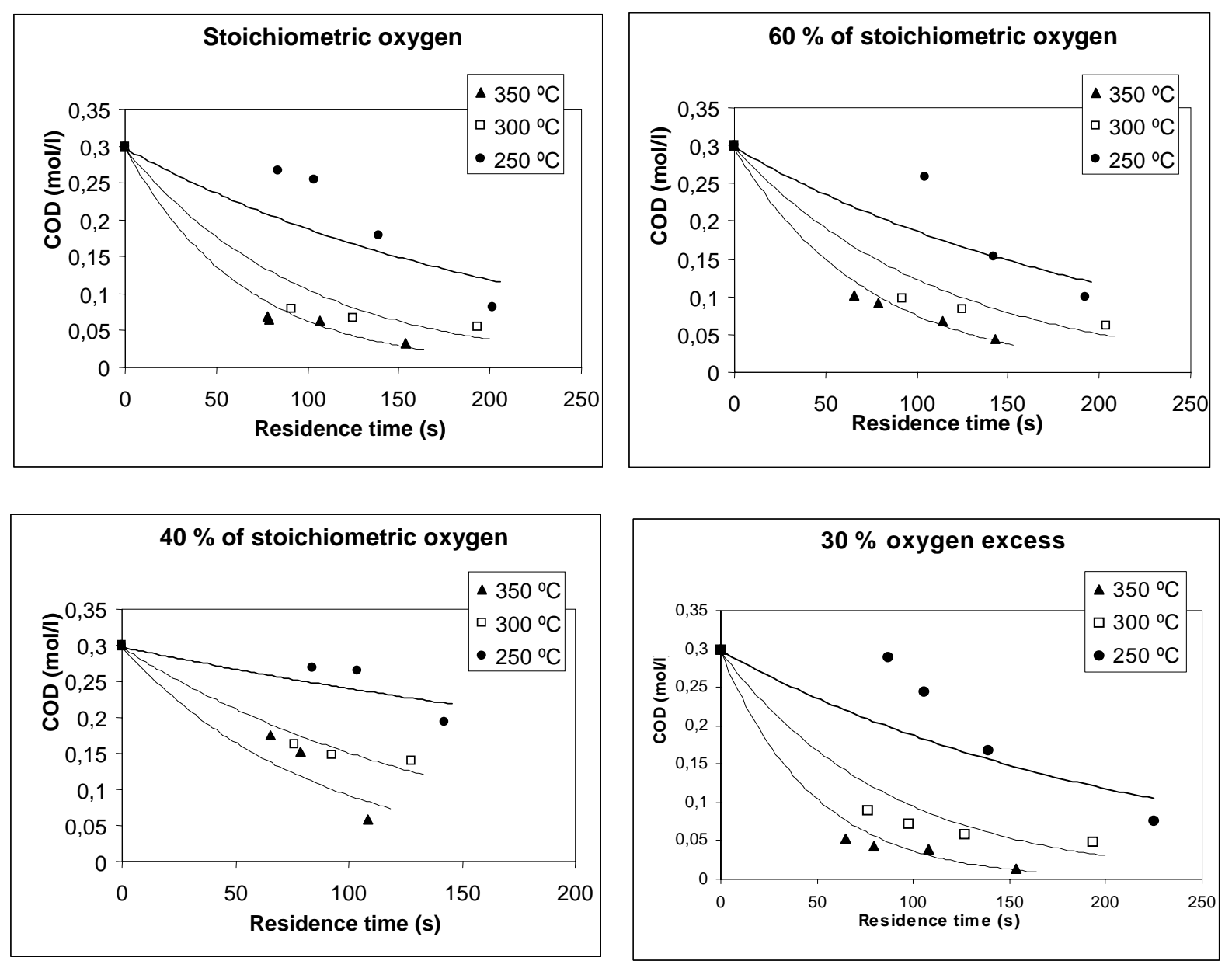

Figure 5 


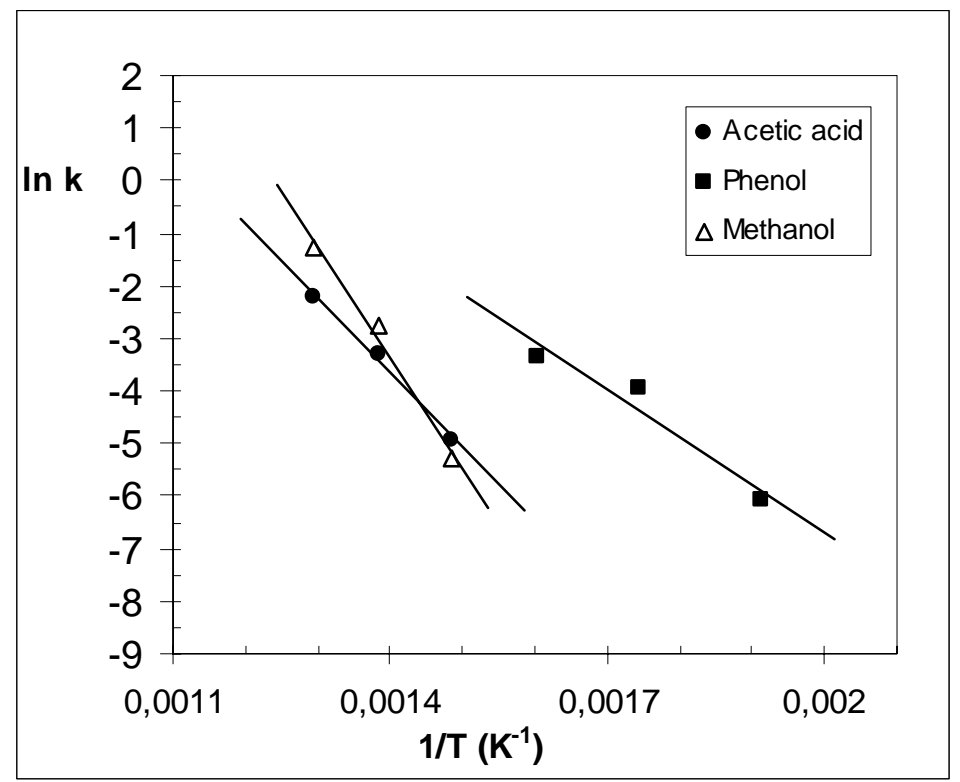

Figure 6 
Table 1 : Kinetic parameters obtained in this work and published in literature. a, b, and c are the reaction orders of organic, oxygen, and water, respectively. T and $\mathrm{P}$ are temperature and pressure, respectively. The reaction rate coefficient $(\mathrm{k})$ is expressed in Arrhenius form, where $\mathrm{A}$ is the pre-exponential factor $\left(\left(\mathrm{mol}^{-1} \mathrm{l}^{-1}\right)^{1-\mathrm{a}-\mathrm{b}-\mathrm{c}} \cdot \mathrm{s}^{-1}\right)$ and $\mathrm{E}_{\mathrm{a}}$ is the activation energy $\left(\mathrm{J} . \mathrm{mol}^{-1}\right) . \mathrm{r}$ is the regression coefficient. 


\begin{tabular}{|c|c|c|c|c|c|c|c|c|c|c|}
\hline $\begin{array}{c}\text { Model } \\
\text { Compound }\end{array}$ & $\begin{array}{c} \\
\left(\left(\mathrm{mol}^{-1}\right)^{1-\mathrm{a}-\mathrm{b}-\mathrm{c}} \cdot \mathrm{s}^{-1}\right)\end{array}$ & $\begin{array}{c}\mathrm{E}_{\mathrm{a}} \\
\left(\mathrm{kJ} . \mathrm{mol}^{-1}\right)\end{array}$ & $\mathbf{r}^{2}$ & $\mathbf{a}$ & $\mathbf{b}$ & c & $\begin{array}{c}\mathbf{T} \\
\left({ }^{\circ} \mathbf{C}\right)\end{array}$ & $\begin{array}{c}\mathbf{P} \\
\text { (MPa) }\end{array}$ & $\begin{array}{c}\text { Conversion rate }{ }^{\mathrm{a}} \\
\left(\mathrm{mol} . \mathrm{s}^{-1}\right)\end{array}$ & Reference \\
\hline $\begin{array}{c}\text { Acetic Acid } \\
\text { Pseudo-first order }\end{array}$ & $\begin{array}{c}(1.5 \pm 0.2) 10^{9} \\
10^{11.1} \\
2.5510^{11}\end{array}$ & $\begin{array}{c}149 \pm 20 \\
183 \\
172.7\end{array}$ & 0.99 & $\begin{array}{l}1 \\
1 \\
1\end{array}$ & $\begin{array}{l}0 \\
0 \\
0\end{array}$ & $\begin{array}{l}0 \\
0 \\
0\end{array}$ & $\begin{array}{l}400-500 \\
425-600 \\
338-445\end{array}$ & $\begin{array}{c}25 \\
24.6 \\
39.4-43.8\end{array}$ & $\begin{array}{l}8.110^{-3} \\
1.610^{-3} \\
1.810^{-2}\end{array}$ & $\begin{array}{c}\text { This work } \\
{[17]} \\
{[18]}\end{array}$ \\
\hline Multi-linear regression & $\begin{array}{c}(7.6 \pm 0.5) 10^{6} \\
7.8410^{9} \\
4.410^{11}\end{array}$ & $\begin{array}{c}115 \pm 6 \\
168 \\
182\end{array}$ & 0.98 & $\begin{array}{c}1 \\
0.72 \\
1\end{array}$ & $\begin{array}{c}0.43 \pm 0.10 \\
0.27 \\
0.3\end{array}$ & $\begin{array}{l}0 \\
0 \\
0\end{array}$ & $\begin{array}{l}400-500 \\
425-600 \\
420-470\end{array}$ & $\begin{array}{c}25 \\
24.6 \\
24\end{array}$ & $\begin{array}{l}7.710^{-3} \\
1.410^{-3} \\
4.810^{-3}\end{array}$ & $\begin{array}{c}\text { This work } \\
\text { [17] } \\
{[19]}\end{array}$ \\
\hline Runge Kutta algorithm & $(3.7 \pm 0.4) 10^{6}$ & $111 \pm 10$ & 0.99 & 1 & $0.39 \pm 0.03$ & 0 & $400-500$ & 25 & $7.510^{-3}$ & This work \\
\hline $\begin{array}{c}\text { Methanol } \\
\text { Pseudo-first order }\end{array}$ & $\begin{array}{c}(6.7 \pm 1.2) \\
10^{11.8}\end{array}$ & $\begin{array}{c}203 \pm 30 \\
178\end{array}$ & 0.99 & $\begin{array}{l}1 \\
1\end{array}$ & $\begin{array}{l}0 \\
0\end{array}$ & $\begin{array}{l}0 \\
0\end{array}$ & $\begin{array}{l}400-500 \\
400-500\end{array}$ & $\begin{array}{c}25 \\
25.3\end{array}$ & $\begin{array}{l}4.510^{-3} \\
1.410^{-2}\end{array}$ & $\begin{array}{c}\text { This work } \\
\text { [20] }\end{array}$ \\
\hline Multi-linear regression & $(4.7 \pm 0.4) 10^{7}$ & $125 \pm 8$ & 0.96 & 1 & $0.31 \pm 0.16$ & 0 & $400-500$ & 25 & $1.110^{-2}$ & This work \\
\hline Runge Kutta algorithm & $(2.4 \pm 0.4) 10^{11}$ & $175 \pm 29$ & 0.99 & 1 & $0.40 \pm 0.02$ & 0 & $400-500$ & 25 & $1.210^{-2}$ & This work \\
\hline $\begin{array}{c}\text { Phenol } \\
\text { Pseudo-first order }\end{array}$ & $(4.2 \pm 1.1) 10^{3}$ & $80 \pm 30$ & 0.94 & 1 & 0 & 0 & $250-350$ & 25 & $3.710^{-3}$ & This work \\
\hline Multi-linear regression & $\begin{array}{c}22 \pm 7 \\
2.6110^{5} \\
10^{1.34}\end{array}$ & $\begin{array}{l}36 \pm 3 \\
63.8 \\
39.2\end{array}$ & 0.95 & $\begin{array}{l}1 \\
1 \\
1\end{array}$ & $\begin{array}{c}0.24 \pm 0.06 \\
1 \\
0\end{array}$ & $\begin{array}{l}0 \\
0 \\
0\end{array}$ & $\begin{array}{l}250-350 \\
284-429 \\
300-500\end{array}$ & $\begin{array}{c}25 \\
29.2-34 \\
25\end{array}$ & $\begin{array}{l}2.810^{-3} \\
6.710^{-3} \\
2.610^{-4}\end{array}$ & $\begin{array}{c}\text { This work } \\
\text { [18] } \\
{[8]}\end{array}$ \\
\hline Runge Kutta algorithm & $(7.5 \pm 1.7) 10^{5}$ & $85 \pm 14$ & 0.97 & 1 & $0.24 \pm 0.05$ & 0 & $250-350$ & 25 & $3.310^{-3}$ & This work \\
\hline
\end{tabular}

- $\quad{ }^{\mathrm{a}}$ Where the conversion rates are calculated from equation 4 with: $[\mathrm{COD}]_{0}=0.3125$ mol..$^{-1}$ or $\left.\left[\mathrm{CH}_{3} \mathrm{COOH}\right]=0.156 \mathrm{~mol}^{-1}{ }^{-1} ; \mathrm{CH}_{3} \mathrm{OH}\right]=$ 0.208 mol..$^{-1} ;\left[\mathrm{C}_{6} \mathrm{H}_{5} \mathrm{OH}\right]=0.045 \mathrm{~mol}^{. \mathrm{l}^{-1}} ;\left[\mathrm{O}_{2}\right]_{0}=0.375 \mathrm{moll}^{-\mathrm{I}^{-1}}$; Temperature of $450^{\circ} \mathrm{C}$ for acetic acid and methanol, and $300{ }^{\circ} \mathrm{C}$ for phenol. 


\section{References}

1 - Cansell F., Rey S. and Beslin P. Thermodynamic aspect of supercritical fluids processing: Applications to polymers and wastes treatment. Revue de l'Institut Français du Pétrole, 1998, vol. 53, p. 71-98.

2 - Cansell F., Beslin P. and Berdeu B. Hydrothermal Oxidation of Model Molecules and Industrial Wastes. Environmental Progress 1998, vol. 17, p. 240-245.

3 - Fromonteil C., Bardelle Ph. and Cansell F. Hydrolysis and oxidation of an epoxy resin in sub- and supercritical water. Ind. Eng. Chem. Res. 2000, vol. 39, p. 922-925.

4 - Mishra V. S., Mahajani V. V. and Joshi J. B. Wet air oxidation. Ind. Eng. Chem. Res. 1995, vol. 34, p. 2-48.

5 - Tester J. W., Holgate H. R., Amellini F. J., Webley P. A., Killilea W. R., Hong G. T. and Barner H. E. Supercritical water oxidation technology. Process development and fundamental research. ACS Symp. Ser. 1993, vol. 518, p. 35-76.

6 - Aymonier C., Beslin P., Jolivalt C. and Cansell F. Hydrothermal oxidation of a nitrogen-containing compound:the fenuron. J. Supercrit. Fluids 2000, vol. 17, p. 4554.

7 - Bottreau M. Hydrothermal oxidation : a new concept for treatment of industrial and urban liquid wastes. In: Supercritical fluids and materials. ed. N. Bonnaudin, F. Cansell and O. Fouassier. Biarritz: Institut national polytechnique de lorraine, 2003. p. 369-384. ISBN 2-905267-39-9.

8 - Portela J. R., Nebot E. and Martinez de la Ossa E. Kinetic comparaison between subcritical and supercritical water oxidation of phenol. Chem. Eng. J. 2001, vol. 81, p. 287-299. 
9 - Dutournier P., Mercadier J., Aymonier C., Gratias A. and Cansell F. Determination of hydrothermal oxidation reaction heats by experimental and simulation investigations. Ind. Eng. Chem. Res. 2001, vol. 40, p. 114-118.

10 - Dutournier P., Aymonier C., Cansell F. and Mercadier J. Experiments and simulations of time-dependant phenomena in a hydrothermal oxidation tubular reactor. Ind. Eng. Chem. Res. 2003, vol. 42, p. 4708-4714.

11 - Mateos D. Transformation de matériaux énergétiques par oxydation hydrothermale : étude cinétique globale et simulation du procédé en régime permanent sur des composés modèles. Th. Doct.: Génie des Procédés: Bordeaux I: 2003

12 - AFNOR. Essais des eaux- Détermination de la demande chimique en oxygène (DCO). Paris: AFNOR, 1988. p. Norme française NF T 90-101.

13 - Vargaftik N.B. Tables on the thermophysical properties of liquids and gases. John Wiley \& Sons, New York, 1975

14 - Scmidt E. Properties of water and steam in SI units, Springer-Verlag, New York, 1989.

15 - Phenix B. D., DiNaro J. L., Tester J. W., Howard J. B. and Smith k. A. The Effects of Mixing and Oxidant Choice on Laboratory-Scale Measurements of Supercritical Water Oxidation Kinetics. Ind. Eng. Chem. Res. 2002, vol. 41, p. 624631.

16 - Mercadier J. Modelling of a chemical reactor working under supercritical conditions. In: Supercritical fluids and materials. ed. N. Bonnaudin, F. Cansell and O. Fouassier. Biarritz: Institut national polytechnique de lorraine, 2003. p. 277-330. ISBN 2-905267-39-9. 
17 -Meyer J. C., Maronne P. A. and Tester J. W. Acetic Acid Oxidation and Hydrolysis in Supercritical Water. AIChE J. 1995, vol. 41, p. 2108-2121.

18 - Li L., Chen P. and F.Gloyna E. Generalized Kinetic Model for Wet Oxidation of Organic Compounds. AIChE J. 1991, vol. 37, p. 1687-1697

19 - Krajnc M., Levec J. The role of catalyst in supercritical water oxidation of acetic acid. Applied catalysis B: Environmental, 1997, vol. 13, p. 93-103.

20 - Anitescu G., Zhang Z., Tavlarides L.L. A kinetic study of methanol oxidation in supercritical water. Ind. Eng. Chem. Res., 1999, vol. 38, p. 2231-2237.

21 - Hydrothermale Oxydation Option (HOO). http://www.hoo-ingenierie.fr/.

22 - Cansell F. Method for treating waste by hydrothermal oxidation, CNRS Patent - WO 0220414. 